\title{
EXPERIÊNCIAS DE ESTÁGIO SUPERVISIONADO OBRIGATÓRIO REALIZADAS NO CURSO DE LICENCIATURA EM QUÍMICA DO INSTITUTO FEDERAL CATARINENSE - CAMPUS ARAQUARI
}

\author{
Marilândes Mól Ribeiro de Melo*, Anelise Grunfeld De Luca \\ *E-mail: marilandes.melo@ifc.edu.br \\ Instituto de Educação, Ciência e Tecnologia Catarinense \\ DOI: $10.15628 /$ rbept.2020.7502 \\ Artigo submetido em: jul/2018 e aceito em mar/2020
}

\begin{abstract}
RESUMO
Os Estágios Supervisionados foram regulamentados na década de 1970, considerando que havia um sério debate nas instituições escolares sobre as atribuições a serem assumidas pelos estagiários. Nesse contexto ocorria que os profissionais eram substituídos por estagiários que recebiam baixas remunerações por possuírem formação incompleta. Com a promulgação da Lei no 11.788 de setembro de 2008, a prática de Estágio Supervisionado foi regulamentada e estabeleceu o caráter educacional dessa atividade formativa. Assim sendo, visa à formação e a inserção do acadêmico na prática profissional de professor, constituindo-se uma referência de conhecimento para o futuro docente e uma oportunidade que as instituições de ensino oferecem para o desenvolvimento de práticas pedagógicas para além da sala de aula; é neste momento que o futuro professor faz sua inserção e reflexões iniciais sobre a profissão. O presente artigo tem como finalidade analisar as experiências de Estágio Supervisionado obrigatório, realizadas no curso de Licenciatura em Química do Instituto Federal Catarinense - Campus Araquari. Este estudo é de cunho qualitativo que utilizou como estratégia de investigação o Estudo de Caso, e como referencial teórico-metodológico pesquisadores como YIN (2015), ANDRÉ (2008), LÜDKE; ANDRÉ (1986), GATTI (2010), LÜDKE; CRUZ (2005), SILVA; OLIVEIRA (2009), ZINKE; GOMES (2015). Para isso, fazemos uma abordagem histórica de constituição do curso, para em seguida debater sobre a concretização do Estágio Supervisionado, descrevendo sua forma de realização, bem com abordando os principais temas e práticas desenvolvidos pelos acadêmicos do referido curso.
\end{abstract}

PALAVRAS-CHAVE: Estágio Supervisionado, práticas pedagógicas, formação do professor.

\section{EXPERIENCES OF MANDATORY SUPERVISED PRACTICE CARRIED OUT IN THE CHEMISTRY COURSE FROM INSTITUTO FEDERAL CATARINENSE - ARAQUARI CAMPUS}

\begin{abstract}
Supervised Practices were regulated in the 1970s, whereas a serious debate was going on educational institutions concerning the responsibilities assumed by trainees. In this context, professionals were replaced by trainees who received low salaries because they had incomplete higher education. With the publication of Law No. 11,788 of September 2008, Supervised Practice was regulated and it established the educational role of this practice. Thus, it aims the educational background and the integration of the student in the practice as a teacher, being a knowledge reference for the future teacher and an opportunity that the educational institutions offer for the development of pedagogical practices beyond the classroom; at this moment the future teacher makes his/her insertion and thoughts on the profession. This article aims to analyze the experiences of mandatory Supervised Internship, carried out in the Chemistry Degree course at the Federal Catarinense Institute - Campus Araquari. This study is of a qualitative nature that used as a research strategy the Case Study, and as a theoretical-methodological framework researchers such as YIN (2015), ANDRÉ (2008), LÜDKE; ANDRÉ (1986), GATTI (2010), LÜDKE; CRUZ (2005), SILVA; OLIVEIRA (2009), ZINKE; GOMES (2015). For this, we make a historical approach to the formation of the course, to then debate about the implementation of the Supervised Internship, describing its form of accomplishment, as well as addressing the main themes and practices developed by the academics of that course.
\end{abstract}

KEYWORDS: Educational practices, Supervised practice, Teacher training. 


\title{
1 ANOTAÇÕES INTRODUTÓRIAS ${ }^{1}$
}

[...] no caso das Licenciaturas em Química, o que ganha importância é a formação do químico e não do professor de Química ou educador químico (SILVA; OLIVEIRA, 2009, p. 44).

Bernardete A. Gatti (2010) ao analisar a formação de professores no Brasil afirma que a articulação de distintos fatores indica que o cenário é preocupante no que diz respeito a essa formação. Ela analisa os seguintes fatores para chegar a tal conclusão: a legislação que rege a formação; as características sociais e educacionais dos "candidatos a professor (a)"; as características dos cursos que formam o professorado e os currículos e o ementário desenvolvido por algumas licenciaturas. A pesquisadora apresenta algumas características sobre o processo formativo do professor e argumenta:

a profissionalidade é o conjunto de características de uma profissão que enfeixam a racionalização dos conhecimentos e habilidades necessárias ao exercício profissional, e que a profissionalização de professores implica a obtenção de um espaço autônomo, próprio à sua profissionalidade, com valor claramente reconhecido pela sociedade (GATTI, 2010, p. 1360).

Ao analisar o crescimento relativo dos cursos de formação de professores entre os anos de 2001 e 2006, Gatti (2010) constatou uma incidência entre 52\% a 94\% de cursos $^{2}$ que perseguem o objetivo de formar professores polivalentes. Ela demonstra também que as universidades são as responsáveis por cerca de " $63 \%$ desses cursos e, quanto ao número de matriculados, a maior parte está nas instituições privadas: $64 \%$ das matrículas em Pedagogia e $54 \%$ das matrículas nas demais licenciaturas" (GATTI, 2010, p. 1361).

Lüdke e Cruz (2005, p. 93) afirmam que os cursos de licenciatura têm sido muito debatidos no cenário educacional. Para elas esses cursos possuem "limitações que cercam sua estruturação". Um dos problemas por elas abordado refere-se à sua estrutura: o "velho" modo $3+1$, que nas suas análises reforçam "o predomínio da formação dos conteúdos em relação à formação pedagógica, provocando a separação entre as duas dimensões e, geralmente, considerando a licenciatura como um apêndice do bacharelado" (LÜDKE; CRUZ, 2005, p. 93). As pesquisadoras mostram ainda que

\begin{abstract}
o currículo dos cursos de formação organizados nessa perspectiva apresenta, geralmente, uma ciência básica, uma ciência aplicada e, finalmente, um espaço de ensino prático, no qual se espera que os alunos aprendam a aplicar o conhecimento adquirido aos problemas da prática cotidiana (LÜDKE; CRUZ, 2005, p. 93).
\end{abstract}

Este modelo formativo não atende completamente às práticas pedagógicas, que por sua complexidade necessitam que as respostas para os problemas sejam oriundos dos próprios contextos nos quais o licenciado atua. Ao chegar à faculdade o aluno se depara com o conhecimento teórico, porém muitas vezes, é difícil relacionar teoria e prática se o licenciando não vivenciar momentos reais nos quais será preciso conviver em sala de aula.

\footnotetext{
${ }^{1}$ Créditos ao professor Dr. Andre Facchini de Souza pela elaboração do abstract deste artigo.

${ }^{2}$ Gatti analisou os cursos de Licenciatura em Pedagogia, Língua Portuguesa, Matemática e Ciências Biológicas. 
Silva e Oliveira (2009) ao analisarem a formação de professores de química demarcam o objetivo dos cursos de Licenciatura em Química:

\begin{abstract}
Tal formação deve contemplar inúmeros aspectos inerentes à formação do bom professor, tais como conhecimento do conteúdo a ser ensinado, conhecimento curricular, conhecimento pedagógico sobre a disciplina escolar Química, conhecimentos sobre a construção do conhecimento científico, especificidades sobre o ensino e a aprendizagem da ciência Química, dentre outros (SILVA; OLIVEIRA, 2009, p. 43).
\end{abstract}

Ressaltam ainda a importância de novas abordagens pedagógicas dos professores formadores, no aspecto de implementar metodologias ativas que promovam a problematização desse conhecimento. A permanência em terreno sólido no que diz respeito à prática pedagógica na área faz emergir críticas aos cursos de Licenciatura de Química, trazendo à baila incertezas sobre "sua validade e eficiência na formação de professores. O perfil profissional esperado de um licenciado em Química parece, em muitos casos, não ser alcançado" (SILVA; OLIVEIRA; 2009, p. 44).

Gatti (2010) em seus estudos afirma que naquilo que diz respeito à escolha pelo curso de licenciatura, exceto a pedagogia, a opção pela docência aparece como "uma espécie de 'seguro desemprego', ou seja, como uma alternativa no caso de não haver possibilidade de exercício de outra atividade" (GATTI, 2010, p. 1361); cerca de $21 \%$ dos licenciandos de outras áreas optam pela licenciatura por falta de outras oportunidades. A mesma pesquisadora argumenta:

\begin{abstract}
Não há consistência em uma profissionalização sem a constituição de uma base sólida de conhecimentos e formas de ação. Com estas conceituações, estamos saindo do improviso, da ideia do professor missionário, do professor quebragalho, do professor artesão, ou tutor, do professor meramente técnico, para adentrar a concepção de um profissional que tem condições de confrontar-se com problemas complexos e variados, estando capacitado para construir soluções em sua ação, mobilizando seus recursos cognitivos e afetivos (GATTI, 2010, p. 1360).
\end{abstract}

Os cursos de licenciatura de acordo com a legislação têm como finalidade formar professores para atuarem na educação básica, ensino fundamental, ensino médio, ensino profissionalizante, educação de jovens e adultos e educação especial. Uma das preocupações com as licenciaturas diz respeito às instituições que oferecem o referido curso, bem como seus currículos e conteúdos ministrados. Muitas vezes a responsabilidade do mau desempenho das redes de ensino recai sobre o professor e a sua formação; cabe lembrar que além desse existem múltiplos fatores que colaboram para a realidade em que o país se encontra na questão da educação (GATTI, 2010).

O Parecer CNE/CP 9/2001, publicado no Diário Oficial da União de 18/1/2002, Seção 1, anuncia um desvio recorrente nos cursos universitários destinados a formar professores:

No caso da formação nos cursos de licenciatura, em seus moldes tradicionais, a ênfase está contida na formação nos conteúdos da área, onde o bacharelado surge como a opção natural que possibilitaria, como apêndice, também, o diploma de licenciado. Neste sentido, nos cursos existentes, é a atuação do físico, do historiador, do biólogo, [...] que ganha importância, sendo que a atuação destes como 'licenciados' torna-se residual e é vista, dentro dos muros da universidade, como 'inferior', em meio à complexidade dos conteúdos da 
'área', passando muito mais como atividade 'vocacional' ou que permitiria grande dose de improviso e auto-formulação do 'jeito de dar aula' (BRASIL, 2002, p. 16).

Marques (2003, p. 172) demonstra que o fato de não se poder separar conteúdo, forma e método, reflete diretamente na questão da separação que os cursos de graduação fazem entre bacharelados e licenciaturas. Estas últimas figuram nos lugares desprivilegiados nas universidades, tendo em vista que são tidas como inaptas na produção do próprio saber; as licenciaturas são lugares para ensino profissionalizante, que prepara para executar tarefas que lhe são impostas por pensamentos e condições externas. São alternativas empobrecidas dos bacharelados, preenchidas por uma formação pedagógica aligeirada, que desconsidera para o ensino-aprendizagem um saber específico, vigilante e fundamentado.

A procura constante por uma formação de qualidade para os profissionais da educação são essenciais para buscar nas escolas e nas salas de aula, melhores oportunidades de formação para as futuras gerações garantindo o seu desenvolvimento. Isto pressupõe questionar a prática recorrente sobre a formação de professores: "[...] ao ser questionada a prática, tem início um processo de aprendizagem que leva a uma mudança comportamental" (MOREIRA; CALEFFE, 2008, p. 13). Jacumasso et al. (2009, p. 2) afirma a existência de

109 cursos voltados para a formação de professores de Química, sendo 79 alocados em instituições públicas. Esses cursos oferecem 3.774 vagas, sendo preenchidas 2.814 com um percentual de formação de apenas $30 \%$ dos ingressantes. Esse baixo percentual de formados em Licenciatura em Química reflete-se diretamente na qualidade do ensino dessa disciplina nas escolas, sendo muitas vezes as vagas ocupadas por professores de outras áreas. Para o ano de 2002 estimou-se que seriam necessários 23.514 professores de Química, entretanto a realidade demonstra que no período de 1990 a 2001, formaram-se apenas 13.559 professores de Química.

Formar quantitativamente em cursos de graduação em Licenciatura em Química é importante; no entanto é a valorização da carreira docente e a adequação da estrutura curricular desses cursos para que possam cumprir as necessidades de uma formação social e política amplas que fazem a diferença. Essas, entre outras medidas, são necessárias para quebrar o estigma de desvalorização e fracasso do sistema escolar brasileiro e da carreira de professor de Química (JACUMASSO, 2009).

Nessa perspectiva o Congresso Nacional instituiu a partir da LDB 9.394/96 (BRASIL, 1996) as condições básicas para a reforma curricular das licenciaturas. O documento "Diretrizes Curriculares Nacionais para a Formação de Professores da Educação Básica" (Resolução CNE/CP N0 01/2002) complementado pela Resolução № 02/2002, que estabelece a carga horária dos cursos de licenciatura, impôs uma mudança curricular drástica aos cursos sem levar em consideração as diferenças de cada instituição e suas estruturas para efetivação dessas mudanças. A formação do professor deve ser um processo ininterrupto: ela não se finda ao se concluir uma licenciatura; no entanto estes precisam oferecer experiências docentes e ações formativas significativas para o futuro docente (SILVA; OLIVEIRA; 2009).

Colocadas estas notas introdutórias, este artigo objetiva analisar as experiências de Estágio Supervisionado obrigatório, realizadas no curso de Licenciatura em Química do Instituto Federal Catarinense - Campus Araquari. Para cumprir esta proposta realizamos uma reflexão sobre a função do estágio supervisionado na formação de 
professores; fazemos uma abordagem histórica da constituição do curso de Licenciatura em Química no IFC - campus Araquari; explicitamos a organização e as características do estágio supervisionado no referido curso; analisamos os principais temas e práticas desenvolvidas pelos acadêmicos em suas vivências de estagio para tecermos algumas conclusões.

\title{
2 O ESTÁGIO SUPERVISIONADO NA FORMAÇÃO DE PROFESSORES
}

\begin{abstract}
[...] teoria-prática é a função principal dos estágios, pois dará ao futuro professor condições para uma ruptura das visões simplistas sobre o ensino de seu conteúdo (CARVALHO, 2012).
\end{abstract}

Os estágios supervisionados foram regulamentados na década de $1970^{3}$, uma vez que havia uma série de discussões nas instituições escolares sobre as atribuições de estagiários. De acordo com a Lei oㅜ 11.788 , de setembro de $2008^{4}$, ocorria neste contexto que os profissionais da atividade eram substituídos por estagiários que recebiam baixas remunerações por possuírem formação incompleta. Porém, com a promulgação da referida Lei, a atividade foi regulamentada e fixou efetivamente o caráter educacional dessa atividade formativa. A Lei no 9.394 de 20 de dezembro de 1996, em seu artigo 82 enfatiza que "os sistemas de ensino estabelecerão as normas de realização de estágio em sua jurisdição". O estágio supervisionado está assim definido na referida Lei no 11.788 :

\begin{abstract}
Art. 1ํ Estágio é ato educativo escolar supervisionado, desenvolvido no ambiente de trabalho, que visa à preparação para o trabalho produtivo de educandos que estejam frequentando o ensino regular em instituições de educação superior, de educação profissional, de ensino médio, da educação especial e dos anos finais do ensino fundamental, na modalidade profissional da educação de jovens e adultos.

$\S 1^{\circ} \bigcirc$ estágio faz parte do projeto pedagógico do curso, além de integrar 0 itinerário formativo do educando.

$\S 2^{0}$ O estágio visa ao aprendizado de competências próprias da atividade profissional e à contextualização curricular, objetivando o desenvolvimento do educando para a vida cidadã e para o trabalho.
\end{abstract}

Assim, o estágio supervisionado visa à formação e a inserção do acadêmico na prática profissional de professor, constituindo-se uma base de conhecimento para 0 futuro docente. É uma oportunidade que as instituições de ensino oferecem ao discente para desenvolver as atividades para além da sala de aula; é o momento no qual o futuro professor faz uma inserção e reflexão inicial sobre a profissão.

Pimenta e Lima (2012) afirmam que no momento de entrada dos estudantes no campo de estágio tem início a apropriação de mecanismos para a compreensão da escola, dos sistemas de ensino e das políticas educacionais, momento este onde 0 estagiário tem a oportunidade de vivenciar o ambiente escolar. Neste mesmo pensamento Barros (et al, 2011) definem que é neste período que o estagiário

\footnotetext{
${ }^{3}$ A Lei no 6.494, de 7 de dezembro de 1977, dispõe sobre os estágios de estudantes de estabelecimentos de ensino superior e profissionalizante do 20 grau e supletivo e dá outras providências.

${ }^{4}$ A Lei no 11.788 , de 25 de setembro de 2008 dispõe sobre o estágio dos estudantes. 
desenvolve competências, voltadas ao desenvolvimento de uma educação de qualidade e que pode contribuir para a transformação social da escola.

Para Pimenta e Lima (2012) o estágio supervisionado é uma oportunidade de convergência das experiências pedagógicas que ocorrem no decorrer do curso. Com base nessas autoras entende-se a importância da prática do estágio como recurso que contribuiu para formar o futuro docente, tendo em vista que proporciona tanto a observação, quanto a intervenção em sala de aula. Ainda acerca da mesma questão os argumentos de Santos e Oliveira orientam que,

\begin{abstract}
Os acadêmicos iniciam sua formação profissional desde o começo do período acadêmico, porém é no estágio supervisionado que realmente se propicia essa preparação para se tornar aptos para trabalhar [... Eles terão conhecimento acerca [do] que ocorre dentro de uma escola e de uma sala de aula, serão capazes de lidar com as dificuldades da rotina escolar (SANTOS; OLIVEIRA, 2012, p. 29).
\end{abstract}

Deste modo, sem o estágio o estudante não estará preparado para o dia a dia de professor (MAFUANI, 2011). Nos argumentos de Bianchi (2005) o estágio supervisionado é uma experiência na qual o estudante mostra sua criatividade, independência e desenvoltura em sala de aula. Essa etapa the proporciona uma oportunidade para perceber se a sua escolha profissional é correspondente com sua aptidão técnica. O estágio supervisionado constitui-se em um espaço no qual o licenciando pode se apropriar dos saberes pedagógicos. Estes saberes de acordo com as análises de Carvalho e Perez

\begin{abstract}
Abrangem um espectro bastante amplo. Alguns estão relacionados ao ensino dos conteúdos escolares, mas são provenientes de pesquisa nos campos da Didática Geral e da Psicologia da Aprendizagem e intimamente relacionados com os acontecimentos dentro da sala de aula influenciando diretamente o ensino e a aprendizagem de todos os conteúdos (CARVALHO; PEREZ, 2015, p. 115).
\end{abstract}

O Parecer CNE/CP № 28/2001, afirma que os estágios supervisionados integram as qualificações "reconhecidas pela CLT, e se inserem dentro das normas gerais conferidas por lei à União. Os estágios supervisionados de ensino também partilham destas qualificações". De acordo com o referido Parecer

\begin{abstract}
A licenciatura é uma licença, ou seja trata-se de uma autorização, permissão ou concessão dada por uma autoridade pública competente para o exercício de uma atividade profissional, em conformidade com a legislação. A rigor, no âmbito do ensino público, esta licença só se completa após o resultado bem sucedido do estágio probatório exigido por lei (BRASIL, 2001).
\end{abstract}

Neste contexto os objetivos dos estágios de modo geral é oportunizar ao estagiário a compreensão, a experiência e a análise das realidades sociais, políticas, culturais e econômicas, dentre outras que circundam o exercício da docência na escola, instigando-os à apropriação de saberes plurais (disciplinares, curriculares, da formação profissional e da experiência), que viabilizarão a compreensão da prática pedagógica que se desenvolve em movimentos mútuos e de complementaridade no aspecto de ensinar e aprender, capacitando-o a agir diante de situações reais conflitivas em sala de aula.

No que diz respeito à formação de professores o Instituto Federal Catarinense (IFC)- Campus Araquari oferta dois cursos: Licenciatura em Química e em Ciências Agrícolas. De acordo com o Projeto Político Pedagógico do Curso (PPCS) de Licenciatura em Química esta formação objetiva 
atender ao mundo do trabalho, suprindo profissionais diferenciados para atuarem na docência da educação básica. O profissional Licenciado em Química também pode dedicar-se à pesquisa acadêmica, visando a geração de novos conhecimentos, materiais didáticos e metodologias ou atuar na área de análises químicas e controle de qualidade, quer no desenvolvimento de novos métodos analíticos, quer na operação de equipamentos. Outra opção é poder atuar nas diversas fases da produção industrial nos mais variados segmentos como farmacêutico, alimentício, de cosméticos, agricultura, siderúrgica, entre outros (IFC/PPCS, 2016, p. 18).

Este objetivo expressa as características que esta instituição vislumbra para o futuro professor. De forma específica os estágios visam:

\footnotetext{
identificar os processos pedagógicos que se desenvolvem na prática social concreta que ocorre nas instituições escolares e também fora delas;

compreender o processo de trabalho pedagógico que ocorre nos espaços escolares formais e informais, bem como as condições de desenvolvimento do aluno;

elaborar projetos e atividades para a escola/sala de aula, atendendo às especificidades de cada situação do desenvolvimento do estágio supervisionado;

conhecer e propor metodologias diferenciadas de ensino, adequando-as à natureza e às características da realidade escolar;

considerar nos projetos e atividades para a escola/sala de aula, as questões da interdisciplinaridade e da contextualização do conhecimento como formas comprometidas com o desenvolvimento do ensino e da aprendizagem dos alunos;
}

viabilizar a criação e o desenvolvimento de métodos e processos diferenciados, visando atingir as metas do Ensino de Química;

desenvolver nos estagiários uma atitude investigativa, por meio de um estágio fundamentado na pesquisa, que instigue a compreensão do que é ensinar, do que é aprender e do que é experienciar a profissão docente (IFC; MANUAL DO ESTÁGIO).

O estágio no IFC pretende assim contribuir para uma formação de qualidade e que forneça ao futuro professor condições de problematizar as realidades escolares e oferecer possíveis formas de resolução das complexidades desse ambiente.

\section{ABORDAGEM HISTÓRICA DA CONSTITUIÇÃO DO CURSO DE LICENCIATURA EM QUIIMICA NO IFC - CAMPUS ARAQUARI}

O IFC tem como qualquer outra Instituição de Ensino Superior (IES) a missão de contribuir para o desenvolvimento socioambiental, econômico e cultural, ofertando uma educação de excelência, pública e gratuita, com ações de ensino, pesquisa e extensão. O percurso histórico do IFC teve início em 26 de fevereiro de 1954, com a instalação da Escola de Iniciação Agrícola "Senador Carlos Gomes de Oliveira", que em 1963 transforma-se no Ginásio Agrícola "Senador Carlos Gomes de Oliveira". Em 1968 o Ginásio Agrícola é transferido para a Universidade Federal de Santa Catarina (UFSC), por força do Decreto $n^{\circ}$ 62.173, de 25 de janeiro de 1968, integrando-se ao Sistema Federal de Ensino, na condição de Colégio Agrícola "Senador Carlos Gomes de 
Oliveira", conforme a Portaria $n^{\circ} 059$, de 24 de julho de 1981 , da Secretaria de $1^{\circ}$ e $2^{\circ}$ Graus do MEC.

Em 29 de dezembro de 2008, foi criado o Instituto Federal Catarinense (IFC), com sede em Blumenau (SC) mediante a integração das Escolas Agrotécnicas Federais de Concórdia, de Rio do Sul e de Sombrio, e os Colégios Agrícolas de Camboriú e "Senador Carlos Gomes de Oliveira" em Araquari, conforme preconiza a Lei № 11.892 de 29 de dezembro de 2008, permitindo que suas unidades passassem a ser Campi. Por força de Lei é uma Autarquia Federal vinculada ao Ministério da Educação, gozando das seguintes prerrogativas: autonomia administrativa, patrimonial, financeira, didáticocientífica e disciplinar.

O IFC - Campus Araquari está localizado na região Norte-Nordeste do Estado de Santa Catarina, cujo epicentro é a cidade de Joinville. Engloba, contudo, dentre outras, Jaraguá do Sul, São Bento do Sul, Rio Negrinho, Barra do Sul, São Francisco do Sul, Barra Velha, Massaranduba e Itaiópolis. A população total da região (incluindo a área de expansão) é de, aproximadamente, 1.100 .000 habitantes, sendo a região com a maior concentração industrial do estado. Há uma presença marcante do setor agropecuarista, da aquicultura, do setor industrial, de turismo e serviços.

O Campus Araquari oferece 05 (cinco) cursos superiores, 03 (três) de Bacharelado (Medicina Veterinária, Sistemas de Informação e Agronomia), 02 (dois) de Licenciatura (Química e Ciências Agrícolas), bem como 02 (dois) Cursos de pósgraduação Lato Sensu (Produção em Aquicultura e Educação em Matemática) e 01 (um) curso de pós-graduação Stricto Sensu (Produção e Sanidade Animal). Além destes, oferece diversos cursos técnicos de nível médio.

Os Institutos Federais assumiram o compromisso, quando na plenitude de seu funcionamento de garantir $20 \%$ de suas matrículas em cursos de licenciaturas, tendo em vista a grande defasagem dos profissionais para determinadas áreas. Neste sentido, os cursos de licenciatura têm como objetivo central a formação de professores para atuarem na Educação Básica, exercendo a docência no Ensino Médio ou no Ensino Médio Integrado.

A falta de docentes preparados é acentuada em algumas disciplinas. No ensino de química, 9,23\% dos professores de Santa Catarina não possuem nível superior. Essas carências são maiores em municípios mais afastados dos centros de formação, em geral, pequenos municípios, com escolas menores. Os docentes sem a qualificação exigida por lei ministram aulas, muitas vezes, para mais de uma turma. Em Santa Catarina, 38,3\% deles ensinam para cinco ou mais turmas.

Desde o final dos anos 1990, o Ministério da Educação e as Secretarias Estaduais de Educação apontam para um acentuado déficit de professores no país na área de Ciências Exatas, em especial para os componentes curriculares de Matemática, Física e Química. Esses dados se confirmam na região de Joinville, Araquari e São Francisco do Sul, verificando-se a atuação de profissionais não habilitados exercendo a docência nessas áreas. Alunos já estão atuando como professores das escolas da educação básica, sem mesmo terem concluído a graduação.

Levando em consideração que os Institutos Federais devem contribuir com o atendimento das demandas crescentes por formação profissional, por difusão de conhecimentos científicos e tecnológicos e de parcerias com os arranjos produtivos locais, o Curso de Licenciatura em Química foi autorizado a funcionar por meio da 
Resolução Ad Referendum n 026 do Conselho Superior do IFC, de 09/09/2010, permitindo-Ihe oferecer 40 vagas por semestre e tem como objetivo atender ao mundo do trabalho, suprindo profissionais diferenciados para atuarem na docência da educação básica. Este objetivo está em consonância com as Políticas Institucionais descritas no Projeto Pedagógico Institucional (PPI) do IFC, que visa constituir-se como centro de referência no apoio à oferta do ensino de ciências nas instituições públicas de ensino, oferecendo capacitação técnica e atualização pedagógica aos docentes das redes públicas de ensino.

O Curso é desenvolvido em 08 (oito) semestres, em regime presencial, sendo que as cargas horárias estão assim distribuídas: formação geral 540h; aprofundamento e diversificação de estudos das áreas de atuação profissional 1.740h; estudos integradores e atividades teórico-práticas 200h; estágio curricular 405h; Prática como Componente Curricular 405h, perfazendo assim um total de 3.290h. O somatório da carga horária dos componentes curriculares atende ao que preconiza Resolução $\mathrm{CNE} / \mathrm{CP}$ 02/2015 para as licenciaturas. Atualmente o Curso de Licenciatura tem aproximadamente 100 alunos frequentando regularmente as aulas e um total de 10 alunos formados. Desde 2011, ano em que o Curso de Licenciatura em Química está funcionando, os estágios supervisionados tem proporcionado a relação teoria e prática.

\title{
4 ORGANIZACCAO E CARACTERÍSTICAS DO ESTÁGIO SUPERVISIONADO NO CURSO DE LICENCIATURA EM QUÍMICA NO IFC - CAMPUS ARAQUARI
}

\begin{abstract}
Observar uma situação pedagógica é olhá-la, fitá-la, mirá-la, admirá-la, para ser iluminado por ela. Observar uma situação pedagógica não é vigiá-la, mas sim fazer vigília por ela, isto é, estar e permanecer acordado por ela na cumplicidade pedagógica (FREIRE, 1992, p. 14).
\end{abstract}

A prática do professor pode, no desenvolvimento dos conteúdos disciplinares, aproximar conteúdos e realidades. Freiberger e Berbel (2010, p. 209) afirmam que "cabe à escola formar pessoas com condições para atuar em uma sociedade cada vez mais complexa". Nesse aspecto, é no Estágio Supervisionado que as instituições formadoras organizam disciplinas, nas quais muitas vezes, ocorrem as primeiras experiências que permitem ao estudante colocar em prática suas habilidades criativas, construir sua autonomia e desinibição em sala de aula.

O Estágio Curricular Obrigatório é aquele definido como tal no Projeto Pedagógico do Curso, cuja carga horária é requisito para aprovação e obtenção de diploma. Terá validade o estágio supervisionado realizado pelo acadêmico na seguinte situação: deverá estar regularmente matriculado no Curso de Licenciatura em Química e na disciplina referente ao respectivo estágio (I, II, III e IV). Para se matricular no Estágio Supervisionado Obrigatório, II, III e IV o acadêmico deverá ter cumprido os pré-requisitos dessas disciplinas; oficializar o termo de compromisso entre o estagiário, a parte concedente do estágio e a instituição de ensino; compatibilizar as atividades desenvolvidas no estágio e aquelas previstas no termo de compromisso.

A duração da carga horária do Estágio Supervisionado Obrigatório é de 405 
(quatrocentas e cinco horas) a partir do início da segunda metade do curso é dividida em quatro disciplinas: Estágio Supervisionado I (90 horas); Estágio Supervisionado II (105 horas); Estágio Supervisionado III (105 horas) e Estágio Supervisionado IV (105 horas).

\title{
4.1 Estágio Supervisionado I: Observação
}

Zinke e Gomes (2015, p. 28656) argumentam que a prática da observação conduz a "uma percepção mais profunda acerca das complexidades existentes na escola e na própria prática docente, abrindo um espaço de reflexão em torno dos principais temas que norteiam a educação e, portanto, é uma parte indispensável na formação docente". Observar não pode ser uma ação vazia, desprovida de finalidade e sentido pedagógico; precisa contribuir para a compreensão da escola como uma instituição complexa, "palco de diversas relações sociais nas quais se abrem um leque de problemas e possibilidades que precisam ser trabalhadas e superadas pelo professor" (ZINKE; GOMES, 2015, p. 28655).

No que diz respeito às múltiplas relações sociais que ocorrem no ambiente escolar Rodrigues (2013, p. 1009) observa quatro visões distintas sobre o estágio supervisionado; o autor designa como "diferentes vozes que estão envolvidas diretamente nos estágios supervisionados de ensino". Para Rodrigues (2013) podem ser assim distinguidas:

\begin{abstract}
A primeira voz será a legal, verificada com base no que é regido pela legislação vigente no Brasil sobre o estágio. A segunda voz será obtida pelo pensamento de alguns teóricos da atualidade sobre o que é o estágio supervisionado e qual a sua função. A terceira voz será a dos alunos que estão em formação inicial, matriculados na disciplina estágio supervisionado. A última voz será a dos professores colaboradores, aqueles que recebem e supervisionam os estagiários nas escolas (RODRIGUES, 2013, p. 1009).
\end{abstract}

É com o objetivo de obter uma percepção mais ampla e equilibrada, dada pela vivacidade das vozes envolvidas que o Estágio de Observação está previsto na disciplina Estágio Supervisionado I, contida na matriz curricular, obedecendo a ementa contida no PPC do curso e que contempla observação da realidade educacional. Serão observados aspectos históricos e políticos do Ensino Médio e Fundamental e do estabelecimento de ensino; também as diretrizes que orientam o trabalho escolar em seu aspecto amplo (orientações legais e documentos oficiais: LDB; DCN; BNCC) e específicos (Projeto Político Pedagógico; diretrizes de funcionamento, plano de gestão). No período de observação o estagiário deverá estar atento ao contexto social, histórico, político e cultural, dentre outros da comunidade atendida pela escola, bem como à sua organização infraestrutural e humana.

O estagiário deverá ainda observar as ações desenvolvidas em caráter coletivo e/ou individual realizadas pelos diferentes profissionais: planejamento do trabalho cotidiano; docência; avaliação e aspectos do cotidiano do ensino de Química (hábitos da sala de aula, a postura do professor, o comportamento dos alunos, o processo de ensino-aprendizagem, a relação entre alunos, metodologia desenvolvida), para posteriormente no Estágio Supervisionado II elaborar um Projeto de Intervenção Pedagógica, fundamentado nas necessidades observadas. Nodari e Almeida afirmam:

É, portanto, pela observação de aulas e de diferentes aspectos de ensino e aprendizagem que ocorre a interação entre professor e estagiário, já que este entra em contato com o universo de papéis distintos desempenhados pelo 
professor, e, na sua relação com a sala de aula, com os alunos e com o professor agente, passa a dividir ideias e tem oportunidade de propor questionamentos, dúvidas e sugestões (NODARI, ALIMEIDA, 2012, p. 25-26).

Pela observação o estagiário assume uma função ativa desempenhando diferentes funções diante das situações diversas com as quais se depara (NODARI, ALIMEIDA, 2012).

\title{
4.2 Estágio Supervisionado II: elaboração do Projeto de Intervenção Pedagógica
}

O projeto de intervenção deverá articular e organizar uma proposta de intervenção seguindo os passos propostos por Deslandes (1994), nos aspectos de definir um conjunto de recortes da realidade social da comunidade escolar e uma metodologia para abordar a realidade: onde intervir; por que intervir; como intervir na realidade observada.

No Estágio Supervisionado II o estagiário deverá dedicar-se à elaboração de um Projeto de Intervenção Pedagógica, fundamentado nas observações realizadas no Estágio Supervisionado I; esta etapa pressupõe a apropriação teórica que dê conta de auxiliar na elaboração do projeto (leitura de artigos; fichamentos; debates). O estagiário apresenta o projeto para seus colegas de disciplina e para uma banca composta por professores da área técnica e da área pedagógica.

É neste estágio que os licenciandos começam a organizar os processos pedagógicos e a constituírem-se autores de sua prática pedagógica, uma vez que esta prática ganha um desenho por meio do aprimoramento da escrita, que é elemento importante na constituição da formação docente, pois a escrita ganha a dimensão diferenciada, significativa e ressonante: passa a ser uma "arma" que precisa ser bem manuseada pelos futuros docentes, que se propõem a trilhar a via acadêmica. Este não é um caminho fácil, uma vez que implica decisão e posição, diante da maneira formal de expressão escrita (BIANCHETTI, 1996).

\subsection{Estágio Supervisionado III: regência compartilhada}

Sobre estágio de regência Carvalho (2012) orienta:

\begin{abstract}
Devem servir de experimentação didática para o aluno-estagiário, sendo então concebidos com o um objeto de investigação, criando condições para que o aluno seja o pesquisador de sua própria prática pedagógica, testando as inovações e sendo um agente de mudança em potencial (CARVALHO, 2012, p $65)$.
\end{abstract}

Assim sendo, as horas destinadas ao estágio de regência compartilhada no curso de licenciatura em Química do IFC, para proporcionar ao estagiário o despertar para a pesquisa, poderão ser distribuídas nas seguintes atividades:

\footnotetext{
I - Regência de classe: pressupõe a iniciação profissional como uma vivência que busca orientar-se por teorias de ensino-aprendizagem para responder às demandas colocadas pela prática pedagógica à qual se dirige;

II - Projetos de extensão: pressupõem a realização de atividades na forma de seminários, minicursos e oficinas para professores, alunos e comunidade escolar ou ainda grupos de educação não-formal sobre temas específicos do curso de licenciatura;
} 
III - Projetos de pesquisa: pressupõem propostas de pesquisa educacional acerca de indagações próprias do processo ensino-aprendizagem e suas especificidades;

IV - Monitorias: pressupõem acompanhamento ao trabalho de educadores em grupos de educação infantil, educação especial, educação de jovens e adultos, grupos da terceira idade, etc. com roteiro e relatórios de atividades;

$\mathrm{V}$ - Seminários temáticos e outras possibilidades da realidade situacional do IFC - Campus Araquari e unidades escolares;

VI - Realização de oficinas pedagógicas, criação de materiais didáticos, visitações a museus e centros de ciências acompanhando alunos, organização de feiras e outras atividades científico-culturais, baseadas nos problemas, necessidades e características da realidade-alvo; orientações de trabalhos de alunos (Feiras de Ciências e das Profissões, Semana da Química, entre outros eventos relacionados);

VIII - Atividades de gestão e organização escolar (participação em elaboração de Projeto Político Pedagógico, reuniões pedagógicas, Conselho Escolar, órgãos colegiados, Associações de Pais e Professores, grupos de trabalho, entre outros);

IX - Elaboração de roteiros de aula prática; elaboração, aplicação e/ou correção de avaliações e exercícios; planejamento e a execução de pequenas aulas, em cooperação com o professor (IFC; MANUAL DE ESTÁGIO, 2017, p. 10-11).

Todo esse volume e diversificação de atividades visa despertar o interesse pela pesquisa. Ghedin et al. (2015, p. 39) demonstram que no estágio o futuro professor "ao mesmo tempo em que entra em contato com os conteúdos conceituais dos saberes que compõem as Ciências" deve também "fazer um exercício dos procedimentos próprios que estas ciências utilizam para se autoproduzirem". Afirmam também:

\begin{abstract}
o processo investigativo é constitutivo de um processo de formação particular que termina por criar estruturas neurológicas que possibilitam ao sujeito moverse no seu contexto com uma visão mais ampla deste. Nesse sentido, a pesquisa compreende que a ação de investigar sistemática e metodicamente constitui como necessário recurso reflexivo capaz de interferir na estrutura cognitiva do professor em formação (GHEDIN et al.; 2015, p. 39).
\end{abstract}

Quando se considera o estágio como recurso do processo formativo do professorpesquisador é preciso pensar nessa prática como coletiva e que objetiva indagar problemas que atingem a escola e reivindicam soluções que podem ser construídas em parceria com as instituições formadoras (GHEDIN et al; 2015, p. 40). Assim,

não há como vincular um processo de estágio a uma dinâmica de pesquisa se os docentes da universidade, os estagiários e os professores das escolas não se tornarem parceiros no processo desta prática, que implica olhares teóricos e epistemológicos, que os dois segmentos devem esforçar-se para compreender (GHEDIN et al; 2015, p. 40).

Com as atividades anteriormente relacionadas, o estagiário do Curso de Licenciatura em Química do IFC deverá cumprir a carga horária da matriz curricular levando em conta a realização de uma ou mais atividades. Deverá também apresentar os resultados parciais do Estágio Supervisionado III em Fórum de Socialização dos Estágios, como resultado de suas investigações iniciais. 


\subsection{Estágio Supervisionado IV: apresentação de artigo final}

No Estágio Supervisionado IV, de apresentação de artigo final, o estagiário deverá apresentar em forma de artigo científico, a sistematização prática e teórica advinda das reflexões de todos os estágios (I, II e III). A elaboração de artigo decorrente do Projeto de Intervenção Pedagógica deverá ser estruturada de acordo com as normas da ABNT e socializado a toda a comunidade acadêmica e externa, por meio de defesa pública. Sobre esta etapa do estágio é importante salientar que a elaboração do artigo promove o exercício intenso de leitura, escrita e análise dos resultados, caracterizando um estágio com pesquisa. O olhar mais pontual frente às questões que envolvem o ensino e aprendizagem da química tem propiciado a reflexão da prática docente considerando situações reais e vivenciadas em sala de aula. $E$ isto é relevante na e para a formação de professores, numa perspectiva reflexiva e de pensar a sala de aula como um espaço de discussão e aprendizado para todos os envolvidos no processo. Também é importante ressaltar que este processo de leitura e escrita do artigo caracteriza-se como um desafio para o licenciando, pois exige estudo e interlocução com autores que debatem sobre a abordagem escolhida, favorecendo a formação do professor pesquisador.

\section{PRINCIPAIS TEMAS E PRÁtICAS DESENVOLVIDOS PELOS ACADÊMICOS}

Mesmo tendo sido o curso de Licenciatura em Química criado em 2011, as primeiras conclusões de estágio supervisionado ocorreram no ano de 2014. Desde este período até 2018, foram concluídos 21 trabalhos relativos a quatro turmas. Este item trata especificamente dos principais temas e práticas desenvolvidos nos estágios pelos acadêmicos e optamos separá-los por ano de conclusão.

No ano de 2014 foram finalizados cinco trabalhos. Os principais temas desenvolvidos pelos estagiários foram os seguintes: "Quimigame: jogo didático como estratégia no processo de ensino e aprendizagem de modelos atômicos", que objetivou "apresentar e discutir os resultados obtidos na intervenção pedagógica referente a aplicação do jogo Quimigame como forma de avaliar o seu uso como ferramenta de avaliação no ensino dos modelos atômicos" (MARTINS; LUCA, 2014); "Elaboração de vídeos pelos alunos de Ensino Técnico de Informática Integrado ao Ensino Médio: possibilidades para o Ensino de Química" com a finalidade de "aperfeiçoar o ensino aprendizagem de química, através da construção de vídeo pelos alunos do ensino técnico de Informática Integrado ao Ensino Médio" (CROSATTI; LUCA; AREND, 2014); "O uso de simuladores computacionais como ferramenta de ensino-aprendizagem na eletroquímica" que visou "averiguar o desenvolvimento de conceitos abstratos da eletroquímica por meio do uso de simuladores educacionais" (LAZZARIS; DIAS; LUCA, 2014); "Interagindo os saberes populares com o saberes científicos através de um estudo envolvendo a fabricação de pão", que buscou "investigar o uso dos saberes populares relacionando-os com os saberes científicos através de estudo envolvendo a fabricação de pão" (SILVA; LUCA; AREND, 2014); "Saberes científicos da Química: uma experiência com o uso de charges e tirinhas como recursos didáticos", cujo objetivo foi analisar o uso de charges e tirinhas como recurso metodológico para incentivar e 
aprimorar o processo de ensino aprendizagem dos saberes científicos da química" (STTFFEN; MELO, 2014).

As estratégias desenvolvidas pelos estagiários mostra a diversidade de recursos pensados para as aulas de química, considerando as problemáticas observadas durante o estágio supervisionado I. Nos registros de observação aparecem declarações da falta de interesse dos alunos, as dificuldades de aprendizagens de conceitos abstratos inerentes ao estudo dos modelos atômicos e da reação de oxidação redução. Estas observações justificaram a escolha de metodologias, atividades e elaboração de recursos didáticos, que foram desenvolvidos com vistas ao ensino e aprendizagem da química. Cunha (2012, p. 92) afirma que "o interesse daquele que aprende passou a ser a força motora do processo de aprendizagem, e o professor, o gerador de situações estimuladoras para aprendizagem".

O desenvolvimento de jogos didáticos tem recebido atenção especial na Educação em Química por ser um "instrumento motivador para a aprendizagem de conhecimentos químicos, à medida que propõe estímulo ao interesse do estudante" (CUNHA, 2012, p. 92). Robaina (2008) explicita que quando o professor recorre ao uso de jogos, está produzindo na sala de aula momentos de participação ativa dos alunos no processo de ensino e aprendizagem, também agindo sobre atitudes e valores. Porém é importante salientar que este recurso nas aulas de química não pode ser entendido como a solução para os problemas de aprendizagem, é preciso perceber que o jogo didático é somente um recurso, necessitando da mediação e do direcionamento pedagógico e conceitual do professor de química.

Da mesma forma pode-se pensar na elaboração de vídeos, charges e tirinhas, bem como uso de simuladores da experimentação. Estas estratégias sozinhas não resolvem os problemas do ensino e aprendizagem, "funcionam" como formas de avaliar, possibilitam debates e novos olhares para o fenômeno estudado, mas ainda assim necessitam das abordagens diferenciadas e contextualizadas do professor.

A valorização dos saberes populares nas aulas de química é importante, pois mobiliza o saber local, saberes da experiência e que transitam nas falas dos alunos, no ambiente escolar e na comunidade na qual a escola está inserida. Chassot (2008, p. 202) declara que "o saber escolar ao invés de ser ensinado de uma maneira asséptica, matematizada e descontextualizada, seja ensinada a partir do saber popular". O saber popular desencadeia ações que transcendem a sala de aula, provocando uma sequência de atividades significativas para os alunos. E então este tipo de abordagem promove debates sobre controvérsias sócio-científicas e investigações sobre o "como" e "por que" das coisas, por meio da valorização dos saberes da comunidade.

Em 2015 quatro estagiários concluíram seus trabalhos: "Da xícara ao Becker: plantas medicinais com recurso didático no ensino de química", que objetivou "analisar as aulas ministradas sobre o conteúdo de química orgânica nas turmas de terceiro ano do ensino Técnico em Informática no Instituto Federal Catarinense - campus Araquari" (VIEIRA; MELO, 2015); "Planejamento e prática pedagógica no ensino de Química: utilização da água como tema gerador de reflexões éticas sobre o meio ambiente", que pretendeu promover reflexões éticas sobre o meio ambiente" (JUNIOR; PACHECO; SOUZA, 2015); "A interface entre os saberes populares na produção do bolo caseiro com os saberes escolares", que priorizou "possibilitar o estudo das reações químicas e das misturas através das receitas caseiras de bolos, utilizando os saberes populares e 
sua relação com os saberes escolares" (SOUZA; LUCA, 2015) e "Analise da abordagem do conceito de quantidade de matéria - MOL em livros de Química do ensino médio do Programa Nacional do Livro Didático (PNLD) (GARCIA, SOUZA, 2015)", a fim de "verificar como o conceito de grandeza quantidade de matéria está sendo abordado e ensinado para estudantes do ensino médio brasileiro".

Os artigos apresentados em 2015, resultado do desenvolvimento das intervenções pedagógicas, mostraram novas estratégias para o ensino de química. As novas abordagens surgem como temas sociais, no caso a utilização da água; mesmo que este tema seja debatido e apresentado na mídia um bom tempo, ainda provoca reflexões quanto à utilização consciente. $\mathrm{E}$ neste quesito, os conhecimentos químicos quanto ao tratamento e seu uso da água são fundamentais e proporcionam o estudo de conceitos químicos essenciais para o entendimento desta problemática. Além disso, é imprescindível que se pense a função social do ensino de química, na inter-relação de dois componentes básicos: a informação química e o contexto social, para que se possa participar da sociedade, não só compreendendo a química, mas a sociedade em que está inserido (SANTOS; SCHNETZLER, 1997).

Outro tema social escolhido "Plantas Medicinais" teve como enfoque a importância da biodiversidade na promoção da saúde, utilizando os conhecimentos químicos dos princípios ativos para estudar a química orgânica. Com esta temática foi possível recuperar os saberes populares dos estudantes e da comunidade na qual a escola está inserida. Também este tema é por excelência interdisciplinar, pois recorre aos conteúdos que não são especificamente da área da química, como: a importância do cultivo de plantas medicinais e os cuidados para com estas plantas. E sobre a interdisciplinaridade é fundamental perceber o que Thiesen (2008, p. 549), explicita: "a interdisciplinaridade não se efetiva se não transcendermos a visão fragmentada e o plano fenomênico, ambos marcados pelo paradigma empirista e positivista". E então, a escola precisa de um movimento que viabilize a "inteligência interdisciplinar", buscando integrar ao invés de ditocomizar, religar no lugar de desconectar, problematizar no lugar de dogmatizar e questionar aquilo que se impõe como verdade absoluta (THIESEN, 2008).

Em se tratando do trabalho da abordagem do conceito de quantidade de matéria MOL é importante salientar que as dificuldades apresentadas pelos estudantes nos entendimentos deste conceito são significativas, tendo em vista seu caráter abstrato. Faz-se necessário desenvolver estratégias didáticas para este assunto, pois a sua compreensão "permite a tradução de um mundo invisível para a realidade cotidiana, possibilitando 0 entendimento das relações quantitativas existentes, em termos microscópicos, entre as substâncias envolvidas numa transformação química" (MARCONDES, LOURENÇO, 2003, p.22). E o trabalho desenvolvido no estágio por (GARCIA, SOUZA, 2015) propiciou além da análise da abordagem do MOL nos livros de Química do ensino médio do Programa Nacional do Livro Didático (PNLD), a elaboração de um vídeo para auxiliar nos entendimentos deste conceito.

Os saberes populares foram contemplados no trabalho de Souza e Luca (2015) relacionando a produção do bolo caseiro com os conceitos de mistura, propriedades físicas e químicas das substâncias e reações químicas no contexto dos estudantes do nono ano do Ensino Fundamental. É importante destacar que a experimentação realizada foi à produção de uma receita de bolo caseiro que os próprios estudantes trouxeram, fomentando debates sobre a seguinte questão: Tem química no bolo? $\mathrm{Na}$ obtenção da resposta os estudantes investigaram vários aspectos relacionados com os 
conteúdos da química: ação dos ingredientes, os componentes da receita, a função de cada uma das substâncias para que o bolo pudesse ficar bonito e gostoso, promovendo o envolvimento dos estudantes nesta atividade. E sobre isso Moraes et al. (2007, p. 1910) ressaltam que " aprender consiste em envolver-se em permanente reconstrução do já conhecido, movimento em que conhecimentos anteriormente construídos servem de ancoras para novos conhecimentos emergentes do processo de aprendizagem". A utilização do tema "Produção do bolo caseiro" foi instigante, pois proporcionou o desenvolvimento de uma sequência didática, na qual os saberes advindos da cultura da comunidade foram sendo transformados em saberes escolares, promovendo a aprendizagem significativa (MOREIRA, 1999).

Os trabalhos concluídos durante o ano de 2016 foram seis: "A química por trás dos alimentos que ingerimos: uma possibilidade de contextualização de conceitos químicos para os estudantes do $9^{\circ}$ ano" (CAMARGO; LUCA: HÖPNER, 2016), que buscou "contextualizar os conceitos químicos relacionados ao estudo dos alimentos"; "Ensino de Química e a experimentação investigativa: alunos do $9^{\circ}$ ano - Química Ambiental" (UHLIG; MOTA, 2016) que objetivou "analisar a experimentação por investigação como contribuidora para o aperfeiçoamento do ensino de Química no 9o quanto à educação ambiental, colaborando para a construção de boas práticas ambientais"; "Jogo QUIMICASA: um recurso didático para o ensino de química" (SOUZA; LUCA; PLACIDO, 2016) cujo objetivo foi "analisar uma proposta de ensino baseado no jogo didático QUIMICASA"; "Problematizando o estudo de soluções por meio da leitura de embalagens/rótulos: uma proposta para o segundo ano do Ensino Médio" (SOETHE; LUCA, 2016) com a finalidade de "favorecer o ensino de soluções através da leitura e interpretação das embalagens/rótulos de produtos de limpeza"; "Tabela Periódica: elemento mediador para ensinar química" (ZERGER; MELO; LUCA, 2016) que buscou "analisar i uso da tabela periódica como elemento mediador do ensino de Química em um turma do $9^{\circ}$ ano"; "O estudo da tabela periódica no $9^{\circ}$ ano: buscando a interface entre história da ciência e Ensino" (MARTINHO; LUCA, 2016), que intencionou "estudar a tabela periódica no 9 $^{\circ}$ ano buscando a interface entre Historia da Ciência e Ensino".

Os trabalhos do estágio do ano de 2016 tiveram uma particularidade: quatro deles foram desenvolvidos para estudantes do nono ano, onde dois deles exploraram a experimentação investigativa com temas de alta vivência dos estudantes: alimentação e efeito estufa. No caso do estudo dos alimentos a experimentação investigativa promoveu as discussões conceituais da química, os aspectos culturais e sociais referentes à alimentação dos estudantes e a promoção da saúde.

O tema efeito estufa ainda é motivo de controvérsias, tendo em vista que geralmente se confundem com o tema camada de ozônio. E então, incluir temas que envolvem as questões ambientais é significativo, pois comumente estes assuntos são somente abordados nas aulas de biologia. Porém a Química tem muito a contribuir na compreensão das reações que ocorrem nos fenômenos e na problemática ambiental como um todo.

Também dois trabalhos foram desenvolvidos numa abordagem da História da Ciência, enfatizando o estudo da tabela periódica. Contudo o mesmo objeto de estudo, promoveu o uso de estratégias distintas; enquanto num trabalho foram proporcionadas as leituras de textos de divulgação científica, no caso: "Tio Tungstênio: memórias de uma infância química", no outro foram abordados aspectos da construção do conhecimento científico por meio do estudo da história da tabela periódica. Tolentino et 
al. (1997, p. 116) afirmam que a "classificação periódica dos elementos surgiu de uma sólida base experimental e passou por etapas que permitiram o despertar da curiosidade científica". A abordagem dos conteúdos a partir da História da Ciência constitui-se uma ferramenta muito importante no ensino, pois permite ao estudante um olhar sob diferentes épocas, possibilitando reflexão sobre o processo de construção do conhecimento científico sob uma nova perspectiva: a ciência não está pronta e acabada.

Outro trabalho enfatizou o estudo das soluções por meio da leitura das embalagens rótulos. Neste caso, a leitura de embalagens de produtos de limpeza constituiu-se de recurso mediador para os entendimentos sobre os conceitos químicos inerentes ao estudo das soluções. Nesta perspectiva promover momentos de leitura, é possibilitar o contato com uma diversidade de gêneros textuais, linguagens e contextos, entendendo que por meio de estratégias de leitura é possível desenvolver a compreensão do lido, analisando, relendo, retomando, discutindo e interpretando o texto. $\mathrm{E}$ neste caso a química pode auxiliar nos entendimentos dos conceitos científicos apresentados nas embalagens/rótulos. Além da leitura e interpretação das informações das embalagens/rótulos de produtos de limpeza, também os estudantes elaboraram vídeos como forma de avaliar o aprendizado.

Outro recurso didático desenvolvido foi o Jogo QUIMICASA, que objetivou relacionar os conceitos estudados na química com o cotidiano do estudante, tendo com enfoque a vivência de uma cozinha. As pesquisas sobre teorias da aprendizagem pontuam que a aplicação de jogos didáticos, em momentos apropriados e convenientes, pode representar o cotidiano e favorecer o processo de ensino e aprendizagem gerando uma relação entre aluno e conteúdo (VIGOTSKI, 1991; MESSEDER NETO, 2016).

Em 2017 tivemos nove trabalhos concluídos: "O tema azia como situação problematizadora para o ensino de química" (RODRIGUES; LUCA, 2017), cujo fim foi "problematizar o tema azia como ponto de partida para o ensino de Química articulando os diversos saberes populares, escolares e científicos"; "Corantes alimentícios como tema gerador de reflexões para o ensino de química" (TOMELIN; SILVA, 2017) que visou "proporcionar novas alternativas contextualizadas utilizando a abordagem dos corantes alimentícios para ensinar Química"; "A experimentação como promotora de aprendizagem do conceito de reação química no nono ano do Ensino Fundamental" (BORBA; LUCA, 2017) que objetivou "abordar os conceitos químicos referentes ao estudo das reações químicas utilizando a experimentação investigativa e a elaboração de vídeos pelos estudantes do $9^{\circ}$ ano do ensino fundamental"; "O ensino de química por meio da problematização do descarte de medicamentos" (RIBEIRO; LUCA, 2017) que intentou "abordar o descarte de medicamentos enfatizando os conceitos químicos relacionados à origem e fabricação, estruturas químicas e as propriedades dos medicamentos e a aprendizagem dos conceitos relacionados às funções orgânicas"; "Problematização do ensino de química por meio de estudos de caso e questões ambientais" (ALBANO; MELO, 2017) que visou "analisar como o estudo de caso envolvendo um olhar sobre questões ambientais contribui para o ensino de química"; "Relações entre o ensino de química e o cotidiano: uma abordagem por meio do uso de produtos de higiene pessoal" (LUCIANO; MELO, 2017) que intencionou "analisar as relações entre o ensino de química e o cotidiano, tendo como prática uma abordagem por meio do uso de produtos de higiene pessoal"; "Preparação de materiais didáticos e a importância das atividades práticas em sala de aula" (REIS; SILVA JUNIOR, 2017), que 
"construir um Liofilizador como recurso didático para intervenções pedagógicas no ensino de química".

Os trabalhos desenvolvidos no ano de 2017 enfatizaram as seguintes estratégias didáticas: experimentação investigativa, elaboração de atividades práticas, temas sociais: azia, corantes alimentícios, descarte de medicamentos, produtos de higiene pessoal e estudo de caso problematizando questões ambientais. Isto demonstra que novos temas e recursos têm sido pensados para a sala de aula, que privilegiam metodologias diferenciadas para o ensino de química.

Os temas sociais contextualizaram o ensino de química possibilitando que os estudantes vivenciassem situações que lhe são próximas, nas quais eles puderam atuar com suas teorias pessoais, promovendo debates e a argumentação dos seus pontos de vista. Além disso, propiciam o planejamento de atividades por parte do professor, que exigem atitudes ativas e um ensino significativo, considerando que são temas da vida cotidiana e merecem ser contemplados nos currículos de química como forma viabilizar o ensino e aprendizagem dos conceitos químicos inerentes a cada assunto abordado: azia, corantes alimentícios, descarte medicamentos, produtos de higiene pessoal.

Outro aspecto a considerar refere-se às escolhas dos conteúdos de química abordados nestes trabalhos de estágios: equilíbrio químico, nomenclatura dos compostos orgânicos, reações químicas, entre outros. Estes conteúdos geralmente são apresentados aos estudantes na forma de quadro e giz, ou leituras do texto do livro didático; essas metodologias são passivas e produzem o desinteresse. Contudo a forma como os estagiários planejaram suas intervenções pedagógicas tornaram-se interessantes, pois atribuíram significado e participação ativa dos estudantes nas aulas, refletindo sobre as atividades propostas tanto nas experimentações, quanto nas sequências didáticas desenvolvidas em sala de aula. Pode-se afirmar que as intervenções pedagógicas produziram conhecimento, motivação e aprendizado.

\section{ANOTAÇÕES FINAIS}

O estágio é a oportunidade que os licenciandos têm de vivenciarem as primeiras experiências permitindo exercerem na prática suas habilidades criativas, construir sua autonomia e desinibição em sala de aula. Ainda constituem-se momentos de revisitar um local conhecido, porém com novo olhar, antes como estudante da Escola Básica e agora como protagonista de algumas ações que serão vivenciadas em sala de aula durante 0 seu desenvolvimento. As experiências vividas impactam a construção de concepções de constituir-se professor; do que seja uma aula e o ato de pedagógico. Isto nos faz refletir sobre as diversas vozes que permeiam o fazer do professor em sala de aula. A formação do professor ocorre na prática, no cuidado com as ações recorrentes nas escolas, nas "caixas pretas", impregnadas de vida que convivem, que são avaliadas e que circulam entre espaços formais, muitas vezes aproveitados pelos estudantes na informalidade e 0 professor precisa aprender a "ler", a "sentir" esses movimentos.

Também é possível constatar que as atividades docentes requerem uma complexa rede de saberes: o que deve ser ensinado e como ensinar; problemas de aprendizagem relacionados a esses saberes; gestão da sala de aula; saberes de censo comum que o aluno traz para a discussão a partir de seu contexto familiar, 
socioeconômico; as políticas públicas que regem a educação e a função do professor; as tecnologias de inovação e comunicação, que interferem (in)diretamente no fazer pedagógico, dentre outras questões (AGUIAR; JUNIOR, 2013).

Assim sendo, a formação docente não se encerra com a finalização do curso, muito menos com as experiências iniciais vivenciadas no estágio supervisionado: é um processo de socializar-se em um ambiente complexo, variável e que demanda adaptação do professor. Neste contexto de implicações é que o estágio se situa, como uma experiência que transcende o que the é próprio, pois a realidade escolar é complexa e oferece um rol de situações que podem ser exploradas e nas quais o licenciando deve extrapolar nas possibilidades de atuação e envolvimento de atividades diferenciadas e inovadoras. É um espaço onde o licenciando pode se aproximar de saberes pedagógicos, que são amplos e estão intimamente relacionados com os acontecimentos da sala de aula e influenciam de maneira direta o ensino e a aprendizagem dos conteúdos (CARVALHO; PEREZ, 2015).

Tessaro e Maceno (2016, p. 34) demonstram que "os estágios também fortalecem a visão crítica dos estudantes sobre os modelos de ensino, e na sua avaliação sobre a pertinência ou não destes modelos para ensinar Química". Neste sentido ainda explicitam que a participação nas atividades e nas rotinas próprias do trabalho docente, permite aos licenciandos a aprendizagem sobre diversificados aspectos pedagógicos, curriculares, avaliativos, além do desenvolvimento de atividades educativas e a sua concretude por meio da regência e dos projetos de ensino planejado (TESSARO: MACENO, 2016). O estágio no IFC pretende assim contribuir para uma formação de qualidade e que forneça ao futuro professor condições de problematizar as realidades escolares e oferecer possíveis formas de resolução das complexidades desse ambiente.

\section{REFERÊNCIAS}

AGUIAR, T. C. de, JUNIOR, W. E. F. Ações e Reflexões Durante o Estágio Supervisionado em Química: Algumas Notas Autobiográficas. Química Nova na Escola. Vol. 35, N 4, p. 283-291, novembro, 2013.

BARROS, José Deomar de Souza; SILVA, Maria de Fátima Pereira da; VÁSQUEZ, Silvestre Fernandes; A Prática docente mediada pelo estágio supervisionado. 2011.

BIANCHETTI, Lucídio. Escrever: uma das armas do professor. In: BIANCHETTI, Lucídio (Org.) Trama e texto. Leitura crítica e escrita criativa. v. 1. São Paulo: Pexus Editora Ltda, 1996.

BIANCHI, A. C. M. Orientações para o Estágio em Licenciatura. São Paulo: Pioneira Thomson Learning, 2005.

BRASIL. MINISTÉRIO DA EDUCAÇÃO. LEI № 11.892, DE 29 DE DEZEMBRO DE 2008. Institui a Rede Federal de Educação Profissional, Científica e Tecnológica, cria os Institutos Federais de Educação, Ciência e Tecnologia, e dá outras providências. 2008. Disponível em: <http://www.planalto.gov.br/ccivil_03/_ato20072010/2008/lei/l11892.htm> (Acesso: 12/07/2018)

BRASIL. MINISTÉRIO DA EDUCAÇÃO. LEI № 9.394 de 20 de dezembro de 1996. LDB 9.394/96. Estabelece as diretrizes e bases da educação nacional. 1996. Disponível em: 
$<$ http://portal.mec.gov.br/seesp/arquivos/pdf/lei9394_Idbn1.pdf> (Acesso: 12/07/2018) BRASIL. MINISTÉRIO DA EDUCAÇÃO. PARECER CNE/CP 9/2001 - Despacho do Ministro em 17/1/2002, publicado no Diário Oficial da União de 18/1/2002, Seção 1, p. 31.

BRASIL. MINISTÉRIO DA EDUCAÇÃO. Parecer CNE/CP № 28/2001. Dá nova redação ao Parecer CNE/CP 21/2001, que estabelece a duração e a carga horária dos cursos de Formação de Professores da Educação Básica, em nível superior, curso de licenciatura, de graduação plena. 2001. Disponível em: <http://portal.mec.gov.br/cne/arquivos/pdf/028.pdf> (Acesso: 12/07/2018)

BRASIL. MINISTÉRIO DA EDUCAÇÃO. RESOLUÇÃO CNE/CP 1, DE 18 DE FEVEREIRO DE 2002. Institui Diretrizes Curriculares Nacionais para a Formação de Professores da Educação Básica, em nível superior, curso de licenciatura, de graduação plena. 2002. Disponível em: <http://portal.mec.gov.br/cne/arquivos/pdf/rcp01_02.pdf> (Acesso: 12/07/2018)

BRASIL. MINISTÉRIO DA EDUCAÇÃO. RESOLUÇÃO CNE/CP № 2, de 19 de Fevereiro de 2002. Institui a duração e a carga horária dos cursos de licenciatura, de graduação plena, de formação de professores da Educação Básica em nível superior. 2002. Disponível em: <http://portal.mec.gov.br/seesp/arquivos/pdf/res2_2.pdf> (Acesso: 12/07/2018)

BRASIL. MINISTÉRIO DA EDUCAÇÃO. RESOLUÇÃO № 2, DE 1ㅇ DE JULHO DE 2015. Define as Diretrizes Curriculares Nacionais para a formação inicial em nível superior (cursos de licenciatura, cursos de formação pedagógica para graduados e cursos de segunda licenciatura) e para a formação continuada. 2015. Disponível em: http://portal.mec.gov.br/docman/agosto-2017-pdf/70431-res-cne-cp-002-03072015pdf/file (Acesso: 12/07/2018)

BRASIL. Presidência da República. LEI № 11.788, DE 25 DE SETEMBRO DE 2008. Dispõe sobre o estágio de estudantes. 2008. Disponível em: <http://www.planalto.gov.br/ccivil_03/_ato2007-2010/2008/lei//11788.htm> (Acesso: 12/07/2018)

CARVALHO, Anna Maria Pessoa de. Os estágios nos cursos de licenciatura. São Paulo, Cengage Learning, 2012 (Coleção ideias em ação).

CARVALHO, Anna Maria Pessoa de; PEREZ, Daniel Gil. O saber e o saber fazer do professor. In: Ensinar a ensinar: didática para a escola fundamental e média. Castro; Carvalho (Orgs). São Paulo, Cengage Learning, 2015.

CHASSOT, A. Saberes primevos fazendo-se saberes escolares. IN: CHASSOT, A. Sete escritos sobre educação e ciência. São Paulo: Cortez, 2008.

CUNHA, M. B. Jogos no ensino de química: considerações teóricas para sua utilização em sala de aula. Química Nova na Escola. v. 34, n. 2, p.92-98, 2012.

DESLANDES, S. F. A Construção do projeto de pesquisa. In: MINAYO, M. C. (Org.) Pesquisa Social. 5. ed. Petrópolis: Vozes, 1994.

FREIBERGER, Regiane Müller; BERBEL, Neusi Aparecida Navas. A importância da pesquisa como princípio educativo na atuação pedagógica de professores de educação infantil e ensino fundamental. In: Cadernos de Educação. FaE/PPGE/UFPel. Pelotas, 
set/dez, 2010.

GHEDIN, Evandro; OLIVEIRA, Elisângela Silva de; ALMEIDA, Whasgthon A. de. Estágio com pesquisa. São Paulo: Cortez, 2015.

FREIRE, M. Observação, Registro, Reflexão: Instrumento Metodológico. Série Seminários. São Paulo: Espaço Pedagógico, 1992.

GATTI, B. A. Formação de professores no Brasil: Características e problemas. Educ. Soc., Campinas, v. 31, n. 113, p. 1355-1379, out.-dez. 2010 1355. Disponível em http://www.cedes.unicamp.br (Acesso em 31/05/2017).

INSTITUTO FEDERAL CATARINENSE. Projeto Pedagógico de Curso Superior (PPCS). Licenciatura em Química. Araquari - Santa Catarina, 2016.

INSTITUTO FEDERAL CATARINENSE. MANUAL DE ESTÁGIO SUPERVISIONADO OBRIGATÓRIO CURSO DE LICENCIATURA EM QUÍMICA, 2017.

JACUMASSO, Sheila Cristina; FREIRE, Leila Inês Follmann; CAMPOS, Sandro Xavier de. A Identificação como Professor e o Futuro do Recém-Formado no Curso de Licenciatura em Química da UEPG: Algumas Análises. 1ํPEQUI - 1ํㅡㄴ CONGRESSO PARANAENSE DE EDUCAÇÃO EM QUIMICA. UEL - 10 A 13 DE AGOSTO DE 2009.

LÜDKE, Menga; CRUZ, Giseli Barreto da. Aproximando universidade e escola de educação básica pela pesquisa. In: Cadernos de Pesquisa. v 35, n 125, p. 81-109. maio/ago, 2005.

MAFUANI, F. Estágio e sua importância para a formação do universitário. Instituto de Ensino superior de Bauru. Editora Nacional, 2011.

MARCONDES, M. E. R.; LOURENÇO I. M. B. Um plano de Ensino para o MOL. Química Nova na Escola, $N^{\circ} 18$, p. 22-25, nov., 2003.

MARQUES, M. O. Formação do profissional da educação. 4. ed. Ijuí: Unijuí, 2003.

MESSEDER NETO, Hélio da Silva. O lúdico no ensino de química na perspectiva histórico-cultural: Além do espetáculo, além da aparência. 1. ed. - Curitiba: Editora Prisma, 2016.

MORAES, R. RAMOS, M. G. GALIAZZI, M. do C. Aprender química: promovendo excursões em discursos da química. In: ZANON, L. B., MALDANER, O. A. (orgs) Fundamentos e propostas de ensino de química para a educação básica no Brasil. ljuí: UNIJUÍ, 2007.

MOREIRA, H.; CALEFFE, L. G. Metodologia da pesquisa para o professor pesquisador. 2.ed. Rio de Janeiro: Lamparina, 2008.

MOREIRA, M. A. Aprendizagem significativa. Brasília: Editora UnB, 1999.

NODARI, Janice Inês; ALMEIDA, Mariza Riva de. Refletindo sobre a agência docente através da observação de aulas. Dossiê Especial Fogaça, F.C \& Nodari, J.I. (ORGS.) Edição Comemorativa 15 Anos do Celin R E V I S T A X , Volume 2, 2012.

PIMENTA, Selma Garrido; LIMA, Maria Socorro Lucena; Estágio e Docência. 7ª ed. São Paulo: Cortez, 2012.

ROBAINA, J. V. L. Química através do lúdico: brincando e aprendendo. Canoas: Ed. ULBRA, 2008. 
RODRIGUES, Micaías Andrade. Quatro diferentes visões sobre o estágio supervisionado. Revista Brasileira de Educação v. 18 n. 55 out.-dez. 2013.

SANTOS, J. L. S; OLIVEIRA, C. M. S. O estágio supervisionado - um momento de fundamental importância no processo de formação profissional. II Congresso de Educação - UEG/UnUI. A formação de professores: uma proposta de pesquisa a partir da reflexão sobre a prática docente. www.cdn.ueg.br/arquivos/ipora/conteudoN/974/CE_2012_06.pdf (Acesso: 07 jul, 2015).

SANTOS, W. L. P. dos; SCHNETZLER, R. P. Educação em química: compromisso com a cidadania. ljuí: Ed. UNIJUÍ, 1997.

SILVA, Camila Silveira da; OLIVEIRA, Luiz Antonio Andrade de. Formação inicial de professores de química: formação específica e pedagógica. In: NARDI, R. org. Ensino de ciências e matemática I: temas sobre a formação de professores [online]. São Paulo: Editora UNESP; São Paulo: Cultura Acadêmica, 2009. 258 p. ISBN 978-85-7983004-4. Available from SciELO Books .

TESSARO, P. S., MACENO, N. G. Estágio Supervisionado em ensino de química. Revista Debates em Ensino de Química - REDEQUIM, v.2, n.2, out, 2016.

THIESEN, J. da S. A interdisciplinaridade como um movimento articulador no processo ensino-aprendizagem. Revista Brasileira de Educação, v. 13 n. 39, p.545-598.set. /dez. 2008.

TOLENTINO, M. ROCHA FILHO, R., CHAGAS, A. P. Alguns aspectos históricos da Classificação periódica dos Elementos Químicos. Química Nova. N.20, 103-111, 1997.

VIGOTSKI, L. S. A formação social da mente. 4르 ed. São Paulo: Editora Ltda, 1991.

ZINKE, Idair Augusto; GOMES, Diana. A prática de observação e a sua importância na formação do professor de geografia. Educere. XII Congresso Nacional de Educação. PUC/Paraná, 2015. 